\title{
Academic Stressors as Predictors of Achievement Goal Orientations of American and ESL International Students
}

\author{
Xi Lin \\ East Carolina University, USA \\ Shu Su \\ Ball State University, USA \\ Alyssa McElwain \\ University of Wyoming, USA
}

\begin{abstract}
This study explores academic stressors and achievement goal orientations of college students, and the relationship between these variables using academic stressors as predictors. As the number of English as a Second Language (ESL) international students has increased rapidly in the US, students' status (American or ESL international) was also examined. A total of 715 students participated in the study from two universities in the US. Results show that ESL international and American students have different achievement goal orientations and academic stressors. Additionally, student status and academic stressors predict college students' various goal orientations. The implications provide useful suggestions to higher education professionals in order to better understand and assist diverse students to succeed in academia.
\end{abstract}

Keywords: academic stress, achievement goal orientation, American students, college students, ESL international students, higher education 


\section{INTRODUCTION}

Achievement goal orientation (AGO) helps explain individual differences in academic motivations, referring to the specific purposes with which students engage in academic work that result in various motivations and achievement-related behaviors (Ames \& Archer, 1988). AGOs are standards that individuals use to determine success (Duda \& Nicholls, 1992; Nicholls, Patashnick, \& Nolen, 1985; Nolen \& Haladyna, 1990), and they play a significant role in students' academic achievement, well-being, and academic engagement. Meanwhile, academic stress is an inevitable part of college students' lives that can influence their academic performance. Studies have explored AGOs and academic stress among college students, but limited research has investigated the relationship between AGOs and academic stress, especially whether academic stressors might predict students' AGOs. Students vary in their motivations, work behaviors, and attitudes toward their academic workload, especially when students are from different cultural backgrounds. English as a second language (ESL) international students have become an important student population in American institutions. Thus, this study also explores whether there is any difference in the relationships between AGOs and academic stress among American and ESL international college students.

\section{THEORETICAL FRAMEWORK}

AGOs are used as the theoretical framework in this study as they have been widely used to explore relationships between students' goals and academic achievement, adjustment, well-being, and engagement in their academic work (Ames, 1992; Aspinwall \& Taylor, 1997; Midgley, Arunkumar, \& Urdan, 1996; Nurmi, SalmelaAro, \& Ruotsalainen, 1994). AGO is comprised of mastery and performance goal orientations. The mastery goal orientation is "a desire to develop competence and increase knowledge and understanding through effortful learning" (K. P. Murphy \& Alexander, 2000), and the performance goal orientation is "a desire to gain favorable judgments of one's competence" (K. P. Murphy \& Alexander, 2000). Approach and avoidance motivations were added on to mastery and performance goal orientations later on (Elliot \& McGregor, 2001) to make it a four-factor model that includes mastery approach, mastery avoidance, performance approach, and performance avoidance (Figure 1). Elliot (2006) defined approach motivations as "the energization of behavior by, or the direction of behavior toward, positive stimuli (objects, events, possibilities)," while the avoidance motivation is "the energization of behavior by, or the direction of behavior away from, negative stimuli (objects, events, possibilities)." According to this $2 \times 2$ model of AGO, students with mastery approach goal orientation prefer mastering academic tasks, while students with mastery avoidance goal orientation intend to avoid misunderstanding an academic task. Performance approach goal-oriented students want to demonstrate that they are more competent than other students, whereas students with performance avoidance goal orientation intend to avoid appearing incompetent in comparison to their peers. 


\section{Definition}

\begin{tabular}{|c|c|c|}
\hline & $\begin{array}{l}\text { Absolute/intrapersonal } \\
\text { (mastery) }\end{array}$ & $\begin{array}{c}\text { Normative } \\
\text { (performance) }\end{array}$ \\
\hline $\begin{array}{c}\text { Positive } \\
\text { (approaching success) }\end{array}$ & $\begin{array}{c}\text { Mastery- } \\
\text { approach goal }\end{array}$ & $\begin{array}{l}\text { Performance- } \\
\text { approach goal }\end{array}$ \\
\hline $\begin{array}{c}\text { Negative } \\
\text { (avoiding failure) }\end{array}$ & $\begin{array}{c}\text { Mastery- } \\
\text { avoidance goal }\end{array}$ & $\begin{array}{l}\text { Performance- } \\
\text { avoidance goal }\end{array}$ \\
\hline
\end{tabular}

\section{Figure 1: An adapted $2 \times 2$ Achievement Goal Framework (Elliot \& McGregor, 2001)}

\section{Achievement Goal Orientations of College Students}

Studies indicate that undergraduate students often adopt both mastery approach and performance avoidance goal orientations (Remedios \& Richardson, 2013). Church, Elliot, and Gable (2001) investigated undergraduate students' adoption of AGOs for courses, and found that students' perceptions of certain characteristics of classroom environments determine their goal adoption. Specifically, students often hold mastery goals when lectures are engaging and when an evaluation focus and harsh evaluation are absent, while they endorse performance approach goals when there is an evaluation focus in the classroom. Additionally, if students perceive a presence of evaluation focus and harsh evaluation, they usually adopt performance avoidance goals. Another study measured the role of AGOs among college students, and the results revealed that those goal orientations contribute unique variance in predicting students' initial and long-term educational outcomes (Harackiewicz, Barron, Tauer, \& Elliot, 2002).

Among college students, international students are often driven by motivations to learn a different culture and language, or to acquire advanced knowledge and skills (Lin \& Wang, 2015). In terms of the AGOs of this population, studies havev identified international students, specifically, ESL international students who study in the US, display both mastery and performance goal orientations, and they often strive for excellence (Shi et al., 2001). For instance, Lou and Noels (2016) examined the goal orientations among 150 university-level students in language learning courses and revealed that ESL students use both mastery and performance approach goal orientations, and those who have a strong intention to learn the target language often have a high level of mastery goal orientations. In addition to varying approaches or motivations to learning, students will invariably experience and cope with academic stress differently. 
This study summarizes that both mastery and performance approach goal orientations are positively associated with college students' motivation and performance in academic courses. Although previous studies explored AGO among college students, limited studies examine AGO by dividing students into American and ESL international student groups, and no known studies investigate the AGOs of ESL international students. As ESL international students have become an important student population in U.S. institutions, investigating the AGOs of these students will fill the gap in the literature and help college service providers better understand and assist them.

\section{Academic Stressors Among College Students}

Stress is an inevitable part of life and it is increasingly prevalent among college students (Blanco et al., 2008; Gallagher, 2012; Mackenzie, et al., 2011). Changes in personal relationships, employment, and finances often bring stress, even if it is positive change (Holmes \& Rahe, 1967). Academic stressors are obvious among college students, which often comes directly from their coursework. These stressors include meeting grade requirements, test taking, the volume of materials to be learned, time management, and job seeking (Crocker \& Luhtanen, 2003; Kumaraswamy, 2013; Misra \& McKean, 2000).

Several factors can lead to academic stressors among university students. For instance, Carveth, Gesse, and Moss (1996) noted that students understand the requirement to develop an extensive knowledge base, yet they perceive they have inadequate time to develop this body of knowledge. Additionally, students who experience academic stress often have less time to study for exams, complete assignments, and master course content. One reason students have less time to focus on academic work is that the majority of college students hold either part-time or fulltime employment with only about $35 \%$ of college students reporting that they do not work (Nonis \& Hudson, 2006). Similarly, Robotham (2009) found that $68 \%$ of the sample held at least one part-time job during term-time and that the majority were employed in excess of $10 \mathrm{hr}$ per week. Specifically, research indicates that students often spend more hours working and fewer hours studying (Nonis \& Hudson, 2006).

Academic stress is also associated with competition among classmates (Abouserie, 1994; Archer \& Lamnin, 1985; Britton \& Tesser, 1991; Kohn \& Frazer, 1986). It is true that competition could drive students to put more effort in school work, but it could also generate unhealthy levels of stress and discourage persistence (Posselt \& Lipson, 2016). In fact, high academic competition among peers is associated with underrepresented students' motivation and self-efficacy (Baldwin, 2009; Washburn \& Miller, 2004). Furthermore, a degree is considered to be a necessary milestone to find a job for college students, thus, job seeking pressure also contributes to students' academic stress as they have to study and obtain the degrees for their future career (Kumaraswamy, 2013). Because of their nonresident status, ESL international students usually find it more difficult to find full-time jobs after graduation than American students in the US (Lee \& Rice, 2007). As a result, job seeking is often a major concern and stressor for many ESL international students who desire to stay in the US after receiving their degrees (Shen \& Herr, 2004). 
Studies indicate that academic stressors can be detrimental to students' mental health (Kumaraswamy, 2013; M. C. Murphy \& Archer, 1996) and academic performance (Campbell, Svenson, \& Jarvis, 1992). For instance, Sohail (2013) examined stress levels and academic performance among 250 first-year medical students and found that academic performance is negatively correlated with level of stress. That is, a higher level of stress is linked to lower academic performance. Moreover, students' perceptions of stress as negative can impair their physical and psychological well-being (M. C. Murphy \& Archer, 1996). Beiter and colleagues (2015) stated that college students must have a healthy attitude toward their academic goals, otherwise students could become overwhelmed by stress. This is important because student mental health contributes largely to the future well-being of society as students enter the workforce (Kumaraswamy, 2013). The level of stress a student faces can vary depending on many personal factors including whether or not they are an ESL international student.

\section{Stressors of ESL International Students}

ESL international students who study in U.S. institutions may encounter general challenges similar to American students such as financial issues, academic coursework, and interpersonal relationships. However, they also may face some unique issues such as language difficulties, cultural differences, and lack of social and academic supports (Baba \& Hosoda, 2014; Brauss, Lin, \& Baker, 2015; Lee \& Rice, 2007). International students usually feel a sense of loss when leaving their families and friends behind and starting from scratch to establish a new and comparable social and academic support system in the US (Sandhu, 1995; Mesidor \& Sly, 2016). These challenges are usually considered primary sources of stress for ESL international students, which can influence academic performance.

\section{Language}

Language difficulty is considered to be the primary challenge for a majority of ESL international students (Mori, 2000; Leong, 2015), which can prevent social interactions with American peers (Hayes \& Lin, 1994). Students from non-English speaking countries, especially from Asian countries, usually struggle with language proficiency in English and this could influence their academic pursuits as they may not effectively embark on their academic programs (Stevens, Emil, \& Yamashita, 2010; Zua, 2016). Additionally, language barriers might also lead to feelings of exclusion by other students during classroom discussions (Lee \& Rice, 2007).

\section{Culture and Social Support}

ESL international students usually come from different cultural backgrounds, and cross-cultural differences in social interactions can make it difficult for them to establish close relationships with local students and find strong social supports (Baba \& Hosoda, 2014; Thurber \& Walton, 2012). When entering a new culture, many ESL international students need to deal with different beliefs and value systems, 
communication patterns, signs and symbols of social contact, and interpersonal relationship patterns (Wu, Garza, \& Guzman, 2015). Wu and colleagues (2015) also noted that stereotypes sometimes lead to prejudice and discrimination, which hinder international students from receiving social support.

Besides, ESL international students often perceive isolation and loneliness when studying in the US (Wu, Garza, \& Guzman, 2015). For example, Yi and colleagues (2003) examined reasons why international students seek counseling services and found that many international students seek help when they have difficulties or psychological concerns and no way to lean on family and friends. However, $\mathrm{Wu}$ and colleagues (2015) noted that sometimes international students are not able to have the support they need because many people were not empathetic for hosting this student population, and counseling services are not widely used by international students.

\section{Culture and Academic Support}

ESL international students' academic experiences are influenced largely by their peers, faculty, and administrators (Pascarella \& Terenzini, 2005). However, many ESL international students encounter difficulties in social interactions because of language and culture barriers; it is very challenging for them to interact with faculty members, college staff, and administrators (Lewthwaite, 1997). Furthermore, ESL international students have been reported to struggle in communicating with instructors because of the differences in collectivism and individualism across cultures. For example, Wu and colleagues (2015) indicated that some international students consider it rude to interrupt a professor when speaking, let alone to disagree or challenge their peers or professors. However, classroom discussion is a very commonly used teaching method in U.S. colleges, and is encouraged by professors. Because international students are afraid of expressing their opinions and avoid confrontation, they are usually considered not actively participating in the class. To bridge this culture gap, international students reported it would be helpful to have professors recognize them and provide more accommodation at the beginning of the class (Wu, Garza, \& Guzman, 2015; Mesidor \& Sly, 2016).

\section{Academic Stressors and Achievement Goal Orientations}

Previous studies note that stressors, especially academic stressors, are negatively associated with motivation (Kleen, Sitorner, Killeen, \& Conrad, 2006). For instance, Liu and $\mathrm{Lu}$ (2011) examined how high school students' academic stress affects their academic motivation in China and found that students' academic stressors negatively predicted intrinsic motivation. However, some studies argued that moderate stress would lead to high achievement motivation (Ramaprabou \& Dash, 2018). Similarly, Struthers and colleagues (2000) investigated 203 college students and found that students' academic stressors have a direct positive relationship with motivation. Meanwhile, others discovered that academic stressors have no significant relationship with achievement motivations among undergraduate students (Karaman, Nelson, \& Cavazos Vela, 2017). Thus, empirical evidence regarding the impact of academic 
stressors on college students' motivation is mixed, and no firm conclusion could be reached.

\section{Current Study}

Due to mixed results in previous research and limited investigations of the relationship between academic stressors and AGOs, it is important to explore whether academic stressors predict college students' AGOs. As more and more international students travel and study in the US (Institute of International Education, 2017), it is also significant to examine their academic stress and goal orientations to better help them thrive in a new culture. Because of cultural influences, the differences in this association between international students and American students is also worth examining. International students are often defined as "nonimmigrant" visitors who choose to undertake all or part of their education (e.g., pursue degrees, take shortterm classes) in a foreign country and move to that country temporarily for studying (Clark, 2009). In this study, we examined international students who were originally from non-English speaking countries and held a nonimmigrant visa to study in U.S. institutions. Finally, as students' goal orientations are meaningfully related to academic outcomes (Mega, Ronconi, \& De Beni, 2014; Vecchione, Alessandri, \& Marsicano, 2014), it is important to explore the relationship of academic stressors and students' goal orientations to help promote better academic outcomes among both American and ESL international students. To address these issues, the research questions guiding this study are:

1. Do American and ESL international students perceive academic stressors differently?

2. Do American and ESL international students have different AGOs?

3. Do levels of perceived academic stressors and student status (American or ESL international students) predict levels of AGOs?

\section{METHODS}

\section{Participants}

The target population of this study is students enrolled in two universities in the US. Student populations in these universities were divided into American and ESL international student samples. In this study, participants who originally came from non-English speaking countries and held nonimmigrant visa during their study are identified as ESL international students. A total number of 754 students participated in this study with 715 usable respondents (usable response rate equals to $94.8 \%$ ).

Most participants were aged between 18 to 23 (92.3\%). Among them, 133 $(18.6 \%)$ reported being international students who originally came from non-English speaking countries including China, Saudi Arabia, South Korea, and Vietnam, and $582(81.4 \%)$ identified themselves as American students. The majority of participants were female students (81.1\%). Additionally, most participants reported enrollment in undergraduate or university accelerator programs (95.3\%) with $30.9 \%$ as freshman, 
$30.1 \%$ as sophomore, $15.8 \%$ as junior, $7.6 \%$ as senior, and $10.9 \%$ as university accelerator programs. An accelerator program involves training ESL international students with intensive academic English skills and/or American culture before beginning regular academic courses. In addition to taking language classes, students in accelerator programs also take one or two regular academic courses each semester in their chosen majors.

\section{Instruments}

\section{Perception of Academic Stress Scale}

The Perception of Academic Stress Scale (PAS) was developed by Bedewy and Gabriel (2015). The PAS is an 18-item 5-point Likert-type scale, ranging from 1 (strongly disagree) to 5 (strongly agree). These items assess four perspectives of students: pressures to perform, perceptions of workload and examinations, selfperceptions, and time restraints. Pressure to perform consists of five items and assesses excessive stress from competitive peer pressures, parents' expectations, and teachers' critical comments on students' performance. Perceptions of workload and examinations consists of four items and measures stressors related to excessive workload, lengthy assignments, and worry about failing exams. Self-perceptions consists of five items and captures academic self-confidence and confidence for success as a student and in their future career and confidence in making good academic decisions. Time restraints is assessed by six items and refers to stressors as a result of limited time allocated to classes, inability to complete homework, difficulty catching up if behind, and limited time to relax. In each subscale of the PAS, higher scores indicate a higher level of stress. Five items were reversed-scored to make consistent with the AGO instrument scoring pattern. This inventory has an original Cronbach's alpha ranging from .5 to .6, and the Cronbach's alpha of the instrument in this study ranges from .60 to .63 .

\section{Achievement Goal Questionnaire}

The Achievement Goal Questionnaire (AGQ) was developed by Elliot and McGregor (2001). The AGQ-R is a 12-item 5-point Likert-type scale, ranging from 1 (strongly disagree) to 5 (strongly agree). These items assess students' four AGOs (mastery approach, mastery avoidance, performance approach, and performance avoidance) regarding their academic performance. According to this $2 \times 2$ model of AGO, mastery approach goal orientation indicates students are interested in truly mastering an academic task. Mastery avoidance goal orientation refers to students who are trying to avoid misunderstanding academic tasks. Students who hold performance approach goal orientations prefer to demonstrate that they are more competent than other students, while performance avoidance goal-oriented students are interested in avoiding appearing more incompetent than their peers. Higher scores imply higher levels of a specific AGO. The original internal consistency Cronbach's alpha of mastery approach goal orientation (MAP), mastery avoidance goal orientation (MAV), performance approach goal orientation (PAP), and performance avoidance 
goal orientation (PAV) were $.84, .88, .92$, and .94, respectively (Elliot \& Murayama, 2008). Cronbach's alpha for each AGO in the current study was .75, .81, .86, and .75, respectively.

\section{Procedure}

Following Institutional Review Board approval, researchers conducted an online survey $(N=754)$ at two universities to assess students' college experiences. Because the majority of international students in the US are from China, the measures were translated into Chinese by two researchers who are fluent in both English and Chinese using the translation and back-translation technique to ensure translation accuracy. The survey allowed participants the language choice of English or Chinese. Data collection took place in March and April 2018 at two universities.

\section{Data Analysis}

Data were analyzed using SPSS 23.0. One-way multiple analyses of variance (MANOVA) was used to explore the levels of PAS and AGOs between American and ESL international students to investigate the first and second research questions. A series of multiple regression using stepwise procedure was conducted to investigate the relationships between predictors (student status and four academic stressors) and criterion variables (four different AGOs) in order to find the best prediction model for each criterion variable. The significant level of Box's M was set as .001 (Mertler \& Vannatta, 2002), whereas the alpha level was set at .05.

\section{RESULTS}

\section{RQ1: Do American and ESL international students perceive academic stressors differently?}

We investigated Research Question 1 by conducting one-way MANOVAs. Box's M test indicated that covariance matrices of the dependent variables were not equal across groups $(p<.001)$, hence Pillai trace was used to assess the multivariate effect. There was a statistically significant difference in AGOs between American and ESL international students with a small effect size, Pillai's Trace $=.03, F(4,708)=4.45$, $p=.001$, partial $\eta_{2}=.03$. Univariate ANOVA follow-up results indicated that only the levels of time restraints, $F(1,713)=9.07, p=.003$, partial $\eta_{2}=.01$, were significantly different between American and ESL international students with a small effect size (see Table 1). Results indicated that American students had a slightly higher level of stress related to time restraints $(M=2.69, S D=0.63)$ than that of ESL international students $(M=2.51, \mathrm{SD}=0.56)$. 
Table 1: Tests of Between-Subjects Effects of Perception of Academic Stress

\begin{tabular}{|c|c|c|c|c|c|c|c|}
\hline \multirow[t]{2}{*}{ Stress } & \multicolumn{2}{|c|}{$\begin{array}{l}\text { American } \\
\text { students } \\
(n=581)\end{array}$} & \multicolumn{2}{|c|}{$\begin{array}{c}\text { ESL } \\
\text { international } \\
\text { students } \\
(n=132)\end{array}$} & \multirow[b]{2}{*}{$F_{(1,713)}$} & \multirow[b]{2}{*}{$p$} & \multirow[b]{2}{*}{ Partial $\eta_{2}$} \\
\hline & $M$ & $S D$ & $M$ & $S D$ & & & \\
\hline Pressure & 2.87 & 0.68 & 2.85 & 0.65 & 1.51 & .70 & $<.001$ \\
\hline Workload & 3.21 & 0.76 & 3.14 & 0.64 & 0.93 & .34 & .001 \\
\hline $\begin{array}{l}\text { Self- } \\
\text { perception }\end{array}$ & 2.50 & 0.69 & 2.60 & 0.62 & 2.18 & .14 & .003 \\
\hline $\begin{array}{l}\text { Time } \\
\text { restraints }\end{array}$ & 2.69 & 0.63 & 2.51 & 0.56 & 9.07 & .003 & .01 \\
\hline
\end{tabular}

\section{RQ2: Do American and ESL international students have different AGOs?}

We investigated Research Question 2 by conducting one-way MANOVAs. Box's $\mathrm{M}$ test indicated that covariance matrices of the dependent variables were not equal across groups $(p<.001)$, hence Pillai trace was used to assess the multivariate effect. There was a statistically significant difference in the AGOs between American and ESL international students with a large effect size, Pillai's Trace $=.242, F(4,708)$ $=56.5, p<.001$, partial $\eta_{2}=.24$.

Univariate ANOVA follow-up results indicated that the level of MAP, $F(1,713)$ $=33.92, p<.001$, partial $\eta_{2}=.06$; PAP, $F(1,713)=4.46, p=.04$, partial $\eta_{2}=.01$; and PAV, $F(1,713)=147.96, p<.001$, partial $\eta_{2}=.17$, were significantly different between American and ESL international students with a small to large effect size (Table 2). The results indicated that ESL international learners had a higher level of MAV and PAP than American learners. However, American students had a higher level of PAV than that of their ESL international counterparts.

Table 2: Tests of Between-Subjects Effects of Achievement Goal Orientations (AGOs)

\begin{tabular}{|c|c|c|c|c|c|c|c|}
\hline \multirow[b]{2}{*}{$\mathrm{AGO}$} & \multicolumn{2}{|c|}{$\begin{array}{l}\text { American } \\
\text { Students } \\
\qquad(n=580)\end{array}$} & \multicolumn{2}{|c|}{$\begin{array}{l}\quad \text { ESL } \\
\text { International } \\
\text { Students } \\
\quad(n=133) \\
\end{array}$} & \multirow[b]{2}{*}{$F_{(1,713)}$} & \multirow[b]{2}{*}{$p$} & \multirow{2}{*}{$\begin{array}{c}\text { Partial } \\
\eta_{2} \\
\end{array}$} \\
\hline & $M$ & $S D$ & $M$ & $S D$ & & & \\
\hline MAP & 3.84 & 0.70 & 3.94 & 0.67 & 2.44 & .12 & .003 \\
\hline MAV & 2.96 & 0.86 & 3.52 & 0.82 & 46.66 & $<.001$ & .06 \\
\hline PAP & 3.07 & 1.00 & 3.27 & 0.77 & 4.46 & .04 & .01 \\
\hline PAV & 4.05 & 0.75 & 3.16 & 0.83 & 147.96 & $<.001$ & .17 \\
\hline
\end{tabular}


Note $:$ MAP = Mastery Approach Goal Orientation; MAV = Mastery Avoidance Goal Orientation; PAP = Performance Approach Goal Orientation; PAV = Performance Avoidance Goal Orientation.

\section{RQ3: Do levels of perceived academic stressors and student status (American or ESL international students) predict of the level of AGOs?}

We conducted a series of multiple regression using stepwise procedure to investigate this research question. American students were coded as 1, and ESL international students were coded as 0 .

\section{Master Approach Goal Orientation}

Results indicate that levels of students' pressures to perform, perceptions of workload and examinations, self-perceptions, and time restraints can predict levels of MAP, $F(4,711)=9.36, p<.001$. Five percent of variance in the level of MAP can be accounted for by the linear combination of the levels of all four academic stressors $\left(R_{2}=.05\right)$. For every unit the level of pressure to perform increases, the level of MAP increases by 0.14 units while the level of other stressors remains the same $(\beta=0.14$, $t[711]=2.91, p=.004)$. For every unit the level of perceptions of workload and examinations increases, the level of MAP increases by 0.10 units while others stays the same $(\beta=0.10, t[711]=2.29, p=.02)$. For every unit the level of self-perceptions increases, the level of MAP decreases by 0.17 units while others stays the same ( $\beta=$ $-0.17, t[711]=-3.91, p<.001)$. For every unit the level of time restrain increases, the level of MAP decrease by 0.20 units while the level of other stressors remains the same $(\beta=-0.20, t[711]=-3.89, p<.001$.

\section{Master Avoidance Goal Orientation}

Results indicate that levels of students' pressures to perform, perceptions of workload and examinations, and student status can predict levels of MAV, $F(3,711)$ $=58.27, p<.001$. Twenty percent of variance in the level of MAP can be accounted for by the linear combination of the levels of these variables $\left(R_{2}=.20\right)$. For every unit the level of pressure to perform increases, the level of MAV increases by 0.19 units while the level of other variables remains the same $(\beta=0.19, t[711]=2.63, p<.001)$. For every unit the level of perceptions of workload and examinations increases, the level of MAV increases by 0.32 units while others stays the same $(\beta=0.32, t(711)=$ $6.75, p<.001)$. Additionally, American students had significantly lower levels of MAV compared with ESL international students $(\beta=-0.59, t[711]=-7.68, p<.001)$.

\section{Performance Approach Goal Orientation}

Results indicate that levels of students' pressures to perform, self-perceptions, and student status can predict levels of PAP, $F(3,711)=39.19, p<.001$. Fourteen percent of variance in the level of MAP can be accounted for by the linear combination of the levels of these variables $\left(R_{2}=.14\right)$. For every unit the level of 
pressure to perform increases, the level of PAP increases by 0.56 units while the level of other variables remains the same $(\beta=0.56, t[711]=10.37, p<.001)$. For every unit the level of self-perceptions increases, the level of PAP decreases by 0.32 units while others stays the same $(\beta=-0.32, t[711]=-5.95, p<.001)$. Additionally, American students had significantly lower levels of PAP compared with ESL international students $(\beta=-0.23, t(711)=-2.71, p=.007)$.

\section{Performance Avoidance Goal Orientation (PAV)}

Results indicate that levels of students' pressures to perform, perceptions of workload and examinations, and student status predict levels of PAV, $F(3,711)=$ $78.35, p<.001$. Twenty-five percent of variance in the level of MAP can be accounted for by the linear combination of the levels of these variables $\left(R_{2}=.25\right)$. For every unit the level of pressure to perform increases, the level of PAV increases by 0.23 units while the level of other variables remains the same $(\beta=0.23, t[711]=4.80, p<.001)$. For every unit the level of perceptions of workload and examinations increases, the level of PAV decreases by 0.15 units while others stays the same $(\beta=0.15, t(711)=$ $3.34, p<.001)$. Additionally, American students had significantly higher levels of PAV compared with ESL international students $(\beta=0.88, t(711)=12.5, p=.001)$.

Table 3: Multiple Regression Results

\begin{tabular}{|c|c|c|c|c|c|c|c|c|}
\hline $\mathrm{DV}$ & $R_{2}$ & $F$ & $d f$ & $p$ & Predictors & $\beta$ & $t(711)$ & $p$ \\
\hline \multirow[t]{4}{*}{ MAP } & .05 & 9.36 & 4,711 & $<.001$ & $\begin{array}{l}\text { Pressures to } \\
\text { perform }\end{array}$ & 0.14 & 2.91 & .004 \\
\hline & & & & & $\begin{array}{l}\text { Perceptions of } \\
\text { workload } \\
\text { and } \\
\text { examinations }\end{array}$ & 0.10 & 2.29 & .02 \\
\hline & & & & & $\begin{array}{l}\text { Self- } \\
\text { perceptions }\end{array}$ & -0.17 & -3.91 & $<.001$ \\
\hline & & & & & Time restrains & -0.20 & -3.89 & $<.001$ \\
\hline \multirow[t]{3}{*}{ MAV } & .20 & 58.27 & 3,711 & $<.001$ & $\begin{array}{l}\text { Pressures to } \\
\text { perform }\end{array}$ & 0.19 & 2.63 & $<.001$ \\
\hline & & & & & $\begin{array}{l}\text { Self- } \\
\text { perceptions }\end{array}$ & 0.32 & 6.75 & $<.001$ \\
\hline & & & & & Student status & -0.59 & -7.68 & $<.001$ \\
\hline \multirow[t]{3}{*}{ PAP } & .14 & 39.19 & 3,711 & $<.001$ & $\begin{array}{l}\text { Pressures to } \\
\text { perform }\end{array}$ & 0.56 & 10.37 & $<.001$ \\
\hline & & & & & $\begin{array}{l}\text { Self- } \\
\text { perceptions }\end{array}$ & -0.32 & -5.95 & $<.001$ \\
\hline & & & & & Student status & -0.23 & -2.71 & .007 \\
\hline \multirow[t]{2}{*}{ PAV } & .25 & 78.35 & 3,711 & $<.001$ & $\begin{array}{l}\text { Pressures to } \\
\text { perform }\end{array}$ & 0.23 & 4.80 & $<.001$ \\
\hline & & & & & $\begin{array}{l}\text { Perceptions of } \\
\text { workload }\end{array}$ & 0.15 & 3.34 & $<.001$ \\
\hline
\end{tabular}




\begin{tabular}{lllllllll}
\hline DV & $R_{2}$ & $F$ & $d f$ & $p$ & Predictors & $\beta$ & $t(711)$ & $p$ \\
\hline \multicolumn{8}{c}{ and } \\
& examinations \\
& & & & \\
& & Student status & 0.88 & 12.5 & .001 \\
\hline
\end{tabular}

\section{DISCUSSION}

Results of this study revealed that ESL international students hold higher levels of mastery goal orientations and performance approach goal orientations than their American counterparts do, whereas American students are more performance avoidance goal-oriented. These findings indicate that ESL international students often have a stronger desire to acquire knowledge and master academic tasks, and they may compete with their peers, while American students are more interested in avoiding appearing that they lack the skills or knowledge to be proficient in a course. Previous studies concluded that better time management usually results in less stress among college students (Nonis, Hudson, Logan, \& Ford, 1998; Schuler, 1979). Specifically, findings of the present study also indicate that American students have a slightly higher level of time restraints compared with ESL international students. This finding implies that American students may have more stressors in terms of managing time to allocate to classes and to finish assignments, and they may have more difficulty to catch up if left behind, and may have less time to relax during the learning process.

In terms of the relationship between academic stress and levels of AGOs, results indicate that students' pressure to perform is a positive predictor of all AGOs among both ESL international and American students. In other words, students' excessive stressors from competitive peer pressures, their parents' expectation, and/or instructors' critical comments on their performance positively influence their motivation in acquiring knowledge and mastering academic tasks. This finding echoes previous studies that academic stressors may potentially motivate students' learning desire and competency (Kumaraswamy, 2013; Murphy \& Archer, 1996).

Additionally, self-perceptions negatively predict mastery approach goal orientations and performance approach goal orientation. This result indicates that students' academic self-confidence, confidence for success in their future career, and confidence in making the right academic decisions influence their intentions to actively master the knowledge. Meanwhile, these types of confidence prevent them from competing with their peers, but positively drive them to avoid misunderstanding of certain knowledge. Students' perceptions of workload and examinations only predict students' performance avoidance goal orientation positively, indicating that a student with a higher level of stressors relating to excessive workload, lengthy assignments, and panic about failing exams would have a high level of intention to learn a course in order to avoid showing that s/he lacks the skills or knowledge to be proficient in this course. This finding in some level demonstrates previous conclusions that students' psychological experiences would be impaired if stress is perceived negatively (Murphy \& Archer, 1996) as their attitudes and intentions toward learning becomes passive. Time restraints only predict mastery approach goal orientation, revealing that fewer stressors of time management would result in a higher level of actively approach learning. 
Finally, students' status predicts levels of the four goal orientations. ESL international students have a higher level of mastery goal orientation and performance approach goal orientation than American students, while American students have a higher level of performance avoidance goal orientation than their ESL international counterparts. These findings indicate that ESL international students are probably more likely to show their competitiveness in learning with other students and they try to avoid misunderstanding or misusing certain knowledge. These findings mirror previous studies that international students, especially ESL students, adopt both mastery and performance approach goal orientations, and these students often strive for excellence (Lou \& Noels, 2016; Shi et al., 2001; Woodrow \& Chapman, 2002). Meanwhile, American students were found to have a lower score of performance avoidance goal orientation, meaning that they tend to avoid showing that they may not learn well in a course compared with their peers. It is possible that peer pressures would contribute to this finding as peer pressures relate with students' performance and competition (Bedewy \& Gabriel, 2015). However, more research is needed.

One factor that may contribute to the findings of the present study is the cultural differences between ESL international students and American students. Most participants in this study who identified as ESL international students came from East Asian countries (e.g., China, Korea). Culture could play an important role in motivating them to compete and succeed. For example, parents in many East Asian countries usually have high expectations for their children to be competitive and become successful in school (Boyd, Hunt, Kandell, \& Lucas, 2003). More research is needed to explore this interpretation.

\section{IMPLICATIONS}

When teaching college students in universities, instructors should establish expectations for students to encourage them to master academic tasks. Because college students often hold performance orientations, competitions or/and group projects could be applied in a course to motivate college students to acquire knowledge. Meanwhile, instructors and advisors should help students to build selfconfidence and provide them a proper guidance during their academic and future career path. Higher educational professionals should also encourage students to use resources such as career centers in order to receive useful suggestions and advice for their academic decisions and future careers.

Additionally, students with a heavier assignment and exam workload are more likely to learn because they try to avoid showing that they lack the skills to learn course content. Therefore, assigning a sufficient amount of work and exams is necessary and helps students maintain positive learning attitudes and build selfconfidence in learning. Finally, higher educational professionals should consider assisting college students to better utilize their time in order to enhance their motivations in actively approaching learning. As mentioned above, it would be helpful to suggest students visit departments such as career centers to get advice regarding balancing their time in and out of class. 


\section{Assisting ESL International Students}

Based on these findings, it is significant for faculty to provide learning materials for ESL international students as they are interested in seeking knowledge and mastering an academic task. Additionally, these students desire to show that they are more competent than their classmates in mastering an academic task. Therefore, a proper use of competition in class would be effective to enhance their learning motivation. In terms of academic stressors, ESL international students would better manage their time to allocate classes and complete homework, and they would have less pressure to catch up if left behind and have more time to relax during the learning process. Therefore, instructors could help these students to improve their time planning and provide enough support and assistance such as available office hours and timely feedback.

\section{Assisting American Students}

During their learning process, American students try to avoid appearing that they lack the skills or knowledge in mastering academic tasks. As a result, instructors should focus on establishing confidence among these students, and to use competition or group projects in class in order to motivate them to learn. In terms of academic stressors, American students tend to worry about using their time efficiently to finish assignments, catch up with others, and/or they may have less time to relax during the learning process. Therefore, instructors should help these students to develop better time management skills. For example, instructors could assist them to set up longterm and/or short-term goals, and weekly timelines or schedules. Instructors should also show enough encouragement and support to these students including office hours and timely feedback.

\section{LIMITATIONS AND FUTURE STUDY}

This study relied on an online self-report questionnaire, so future research should include qualitative studies such as focus groups or interviews to further explore stressors and AGOs of ESL international and American students. This could illuminate additional findings not shown through quantitative survey data. Additionally, data was collected from two research institutions in the US; therefore, results do not represent all college students in America. Furthermore, most participants in this study were enrolled in undergraduate programs and most of them were female students; therefore, these results may not be generalized to diverse audiences or graduate students. As a consequence, more diverse students should be recruited in future research to explore the association between academic stressors and AGOs. Furthermore, this study only took student status (ESL international or American) into consideration; other variables that may influence their stress and AGOs are not included. Home cultures may also associate with students' academic stress and motivations to learn. Therefore, factors including degrees, gender, majors, and/or cultures should be included to further examine whether those variables have an influence on the relationships between these variables. Finally, students who take 
accelerated programs before enrolling into the regular academic programs may have different stressors compared to those who are already in regular degree programs. Future studies should also distinguish students from these programs.

In conclusion, this study examined associations between academic stressors and AGOs of college students. Students' status (ESL international vs. American) was specifically explored as ESL international students have become an important student population in U.S. institutions. Results also indicate that ESL international and American students hold different AGOs, and these two student groups experience different academic stressors. Additionally, student status and academic stressors predict AGOs among college students. Results can help enhance the understanding of these two student groups among higher educational professionals and may help motivate instructors and institutions to better assist international students to succeed in academia.

\section{REFERENCES}

Abouserie, R. (1994). Sources and levels of stress in relation to locus of control and self-esteem in university students. Educational Psychology, 14(3), 323-330. doi: $10.1080 / 014434194014306$

Ames, C. (1992). Classrooms: Goals, structures, and student motivation. Journal of Educational Psychology, 84(3), 261-271. doi:10.1037/0022-0663.80.3.260

Ames, C., \& Archer, J. (1988). Achievement goals in the classroom: Students' learning strategies and motivation processes. Journal of Educational Psychology, 80(3), 260-267. doi:10.1037/0022-0663.80.3.260

Archer, J., Jr, \& Lamnin, A. (1985). An investigation of personal and academic stressors on college campuses. Journal of College Student Personnel, 26, 210 215.

Aspinwall, L. G., \& Taylor, S. E. (1997). A stitch in time: Self-regulation and proactive coping. Psychological Bulletin, 121(3), 417-436. doi:10.1037/00332909.121.3.417

Baba, Y., \& Hosoda, M. (2014). Home away home: Better understanding of the role of social support in predicting cross-cultural adjustment among international students. College Student Journal, 48(1), 1-15.

Baldwin, R. G. (2009). The climate for undergraduate teaching and learning in STEM fields. New Directions for Teaching and Learning, 117, 9-17.

Bedewy, D., \& Gabriel, A. (2015). Examining perceptions of academic stress and its sources among university students: The perception of academic stress scale. Health Psychology Open, 2(2), 1-9. doi:10.1177/2055102915596714

Beiter, R., Nash, R., McCrady, M., Rhoades, D., Linscomb, M., Clarahan, M., \& Sammut, S. (2015). The prevalence and correlates of depression, anxiety, and stress in a sample of college students. Journal of Affective Disorders, 173, 90 96. doi:10.1016/j.jad.2014.10.054

Blanco, C., Okuda, M., Wright, C., Hasin, D., Grant, B., Liu, S., \& Olfson, M. (2008). Mental health of college students and their non-college-attending peers: Results from the national epidemiologic study on alcohol and related conditions. 


Archives of General Psychiatry, 65(12), 1429-1437.
doi:10.1001/archpsyc.65.12.1429

Boyd, V. S., Hunt, P. F., Kandell, J. J., \& Lucas, M. S. (2003). Relationship between identity processing style and academic success in undergraduate students. Journal of College Student Development, 44(2), 155-167. doi:10.1353/csd.2003.0012

Brauss, M. R., Lin, X., \& Baker, B. A. (2015). International students in higher education: Educational and social experiences. Institute for Learning Styles Journal, 1, 54-71.

Britton, B. K., \& Tesser, A. (1991). Effects of time-management practices on college grades. Journal of Educational Psychology, 83(3), 405-410. doi:10.1037/00220663.3.405

Campbell, R. L., Svenson, L. W., \& Jarvis, G. K. (1992). Perceived level of stress among university undergraduate students in Edmonton, Canada. Perceptual and Motor Skills, 75(2), 552--554. doi:10.2466/pms.1992.75.2.552

Carveth, J. A., Gesse, T., \& Moss, N. (1996). Survival strategies for nurse-midwifery students. Journal of Nurse-Midwifery, 4l(1), 50-54. doi:10.1016/00912182(95)00072-0

Church, M. A., Elliot, A. J., \& Gable, S. L. (2001). Perceptions of classroom environment, achievement goals, and achievement outcomes. Journal of Educational Psychology, 93(1), 43-54. doi:10.1037/0022-0663.93.1.43

Clark, N. (2009, September 1). What defines an international student? A look behind the numbers. Retrieved from https://wenr.wes.org/2009/09/wenr-september2009-feature

Crocker, J., \& Luhtanen, R. K. (2003). Level of self-esteem and contingencies of selfworth: Unique effects on academic, social, and financial problems in college students. Personality and Social Psychology Bulletin, 29(6), 701-712. doi: $10.1177 / 0146167203252881$

Duda, J. L., \& Nicholls, J. G. (1992). Dimensions of achievement motivation in schoolwork and sport. Journal of Educational Psychology, 84(3), 290-299. doi:10.1037/0022-0663.84.3.290

Elliot, A. J. (2006). The hierarchical model of approach-avoidance motivation. Motivation and Emotion, 30(2), 111-116. doi:10.1007/s11031-006-9028-7

Elliot, A. J., \& McGregor, J. A. (2001). A 2x2 achievement goal framework. Journal of Personality and Social Psychology, 80(3), 501-519. doi:10.1037//00223514.80.3.501

Elliot, A. J., \& Murayama, K. (2008). On the measurement of achievement goals: Critique, illustration, and application. Journal of Educational Psychology, $100(3), 613-628$.

Gallagher, R. P. (2012). Thirty years of the national survey of counseling center directors: A personal account. Journal of College Student Psychotherapy, 26(3), 172-184. doi:10.1080/87568225.2012.685852

Harackiewicz, J. M., Barron, K. E., Tauer, J. M., \& Elliot, A. J. (2002). Predicting success in college: A longitudinal study of achievement goals and ability measures as predictors of interest and performance from freshman year through 
graduation. Journal of Educational Psychology, 94(3), 562-575. doi:10.1037/0022-0663.94.3.562

Hayes, R.L., \& Lin, H.R. (1994). Coming to America: Developing social support systems for international students. Journal of Multicultural Counseling and Development, 22(1), 7-16. doi:10.1002/j.2161-1912.1994.tb00238.x

Holmes, T. H., \& Rahe, R. H. (1967). The social readjustment rating scale. Journal of Psychosomatic Research, 11(2), 213-218. doi:10.1016/0022-3999(67)900104

Institute of International Education. (2017). Open doors report on international educational exchange. Retrieved from http://www.iie.org/opendoors

Karaman, M. A., Nelson, K. M., \& Cavazos Vela, J. (2017). The mediation effects of achievement motivation and locus of control between academic stress and life satisfaction in undergraduate students. British Journal of Guidance \& Counselling, 46(4), 375-384. doi:10.1080/03069885.2017.1346233

Kleen, J. K., Sitomer, M. T., Killeen, P. R., \& Conrad, C. D. (2006). Chronic stress impairs spatial memory and motivation for reward without disrupting motor ability and motivation to explore. Behavioral Neuroscience, 120(4), 842-851. doi:10.1037/0735-7044.120.4.842

Kohn, J. P., \& Frazer, G. H. (1986). An academic stress scale: Identification and rated importance of academic stressors. Psychological Reports, 59(2), 415-426. doi:10.2466/pr0.1986.59.2.415

Kumaraswamy, N. (2013). Academic stress, anxiety and depression among college students: A brief review. International Review of Social Sciences and Humanities, 5(1), 135-143.

Lee, J. J., \& Rice, C. (2007). Welcome to America?: International student perceptions of discrimination. Higher Education, 53(3), 381-409. doi:10.1007/S10734-0054508-3

Leong, P. (2015). Coming to America: Assessing the patterns of acculturation, friendship formation, and the academic experiences of international students at a U.S. college. Journal of International Students, 5(4), 459-474.

Lewthwaite, M. (1997). A study of international students' perspectives on crosscultural adaptation. International Journal for the Advancement of Counseling, 19, 167-185.

Lin, X., \& Wang, C. H. (2015). Factors that affect returning to graduate school for international and American adult learners. Institute for Learning Styles Journal, $1,40-53$.

Liu, Y., \& Lu, Z. (2011). The Chinese high school student's stress in the school and academic achievement. Educational Psychology, 31(1), 27-35. doi:10.1080/01443410/2010/513959

Lou, N. M., \& Noels, K. A. (2016). Changing language mindsets: Implications for goal orientations and responses to failure in and outside the second language classroom. Contemporary Educational Psychology, 46, 22-33. doi:10.1016/j.cedpsych.2016.03.004

Mackenzie, S., Wiegel, J. R., Mundt, M., Brown, D., Saewyc, E., Heiligenstein, E., ... Fleming, M. (2011). Depression and suicide ideation among students 
accessing campus health care. American Journal of Orthopsychiatry, 81(1), 101107. doi:10.1111/j.1939-0025.2010.01077.x

Mega, C., Ronconi, L., \& De Beni, R. (2014). What makes a good student? How emotions, self-regulated learning, and motivation contribute to academic achievement. Journal of Educational Psychology, 106(1), 121-131. doi:10.1037/a0033546

Mertler, C. A., \& Vannatta, R. A. (2002). Advanced and multivariate statistical methods: Practical application and interpretation. Los Angeles: Pyrczak.

Mesidor, J. K., \& Sly, K. F. (2016). Factors that contribute to the adjustment of international students. Journal of International Students, 6(1), 262-282.

Midgley, C., Arunkumar, R., \& Urdan, T. C. (1996). If I don't do well tomorrow, there's a reason: Predictors of adolescents' use of academic self-handicapping strategies. Journal of Educational Psychology, 88(3), 423-434. doi: $10.1037 / 0022-0663.88 .3 .423$

Misra, R., \& McKean, M. (2000). College students' academic stress and its relation to their anxiety, time management, and leisure satisfaction. American Journal of Health Studies, 16(1), 41-51.

Mori, S. (2000). Addressing the mental health concerns of international students. Journal of Counseling \& Development, 78(2), 137-144. doi:10.1002/j.15566676.2000.tb02571.x

Murphy, K. P., \& Alexander, P. (2000). A motivated exploration of motivation terminology. Contemporary Educational Psychology, 25(1), 3-53. doi:10.1006/ceps.1999.1019

Murphy, M. C., \& Archer, J., Jr. (1996). Stressors on the college campus: A comparison of 1985 and 1993. Journal of College Student Development, 37(1), 20-28.

Nicholls, J. G., Patashnick, M., \& Nolen, S. B. (1985). Adolescents' theories of education. Journal of Educational Psychology, 77(6), 683-692. doi:10.1037/0022-0663.77.6.683

Nolen, S. B., \& Haladyna, T. M. (1990). Personal and environmental influences on students' beliefs about effective study strategies. Contemporary Educational Psychology, 15(2), 116-130. doi:10.1016/0361-476X(90)90011-O

Nonis, S. A., \& Hudson, G. I. (2006). Academic performance of college students: Influence of time spent studying and working. Journal of Education for Business, 81(3), 151-159. doi:10.3200/JOEB.81.3.151-159

Nonis, S. A., Hudson, G. I., Logan, L. B., \& Ford, C. W. (1998). Influence of perceived control over time on college students' stress and stress-related outcomes. Research in Higher Education, 39(5), 587-605. doi:10.1023/A:1018753706925

Nurmi, J. E., Salmela-Aro, K., \& Ruotsalainen, H. (1994). Cognitive and attributional strategies among unemployed young adults: A case of the failure-trap strategy. European Journal of Personality, 8(2), 135-148. doi:10.1002/per.2410080205

Pascarella, F. T., \& Terrenzini, P. T. (2005). How college affects students: A third decade of research (1st ed.). San Francisco: Jossey-Bass.

Posselt, J. R., \& Lipson, S. K. (2016). Competition, anxiety, and depression in the college classroom: Variations by student identity and field of study. 
Journal of College Student Development, 57(8), 973-989. doi:10.1353/csd.2016.0094

Ramaprabou, V., \& Dash, S. K. (2018). Effect of academic stress on achievement motivation among college students. Journal on Educational Psychology, 11(4), 32-37. doi:10.

Remedios, R., \& Richardson, J. T. E. (2013). Achievement goals in adult learners: Evidence from distance education. British Journal of Educational Psychology, 83(4), 664-685. doi:10.1111/bjep.12001

Robotham, D. (2009). Combining study and employment: A step too far? Education and Training, 51(4), 322-332. doi:10.1108/00400910968337

Sandhu, D. S. (1995) An examination of the psychological needs of the international students: Implications for counseling and psychotherapy. International Journal for the Advancement of Counselling, 17, 229-239.

Schuler, R. S. (1979). Managing stress means managing time: The two are so intertwined that controlling one can only help the other. Personal Journal, 58, 851-854.

Shen, Y. J., \& Herr, E. L. (2004). Career placement concerns of international graduate students: A qualitative study. Journal of Career Development, 31(1), 15-29.

Shi, K., Wang, P., Wang, W., Zuo, Y., Liu, D., Maehr, M. L., ... Hruda, L. (2001). Goals and motivation of Chinese students: Testing the adaptive learning model. In F. Salili, C. Chiu, \& Y. Y. Hong (Eds.), Student motivation: The culture and context of learning (pp. 249-270). New York: Plenum.

Sohail, N. (2013). Stress and academic performance among medical students. Journal of the College of Physicians and Surgeons Pakistan, 23(1), 67-71.

Stevens, D. D., Emil, S., \& Yamashita, M. (2010). Mentoring through reflective journal writing: A qualitative study by a mentor/professor and two international graduate students. Reflective Practice, 11(3), 347-367. doi:10.1080/14623943.2010.490069

Struthers, C. W., Perry, R. P., \& Menec, V. H. (2000). An examination of the relationship among academic stress, coping, motivation, and performance in college. Research in Higher Education, 41(5), 581-592. doi:10.1023/A:1007094931292

Thurber, C. A., \& Walton, E. A. (2012). Homesickness and adjustment in university students. Journal of American College Health, 60(5), 415-419. doi:10.1080/07448481.2012.673520

Vecchione, M., Alessandri, G., \& Marsicano, G. (2014). Academic motivation predicts educational attainment: Does gender make a difference? Learning and Individual Differences, 32, 124-131.

Washburn, M. H., \& Miller, S. G. (2004). Retaining undergraduate women in science, engineering, and technology: A survey of a student organization. Journal of College Student Retention: Research, Theory \& Practice, 6, 155-168.

Woodrow, L., \& Chapman, E. (2002). Assessing the motivational goal orientations of international English for academic purposes (EAP) students. Current Research in Social Psychology, 7(15), 257-274. 
Wu, H. P., Garza, E., \& Guzman, N. (2015). International student's challenge and adjustment to college. Education Research International, 2015, 202753. doi: $10.1155 / 2015 / 202753$

Yi, J. K., Lin, J. C. G., Jenny, K., \& Kishimoto, Y. (2003). Utilization of counseling services by international students. Journal of Instructional Psychology, 30(4), 333-342.

Zua, B. (2016). The impact of language proficiency on the academic achievement of international students. International Journal of Education and Human Developments, 2(6), 33-43.

XI LIN, $\mathrm{PhD}$, is an assistant professor at the Department of Interdisciplinary Professions at East Carolina University. Her research focuses on online and distance learning as well as game-based learning. She also investigates cross-cultural adaptation and mobility of international students and faculty in the US institutions. Email: linxi18@ecu.edu

SHU SU, PhD, is an assistant professor at the Department of Early Childhood, Youth, and Family Studies at Ball State University. Her research takes a multidisciplinary approach towards understanding the role of parenting and peer relationships in the youth social development at different life stage (i.e., childhood, adolescence, emerging adulthood). Email: ssu@ bsu.edu

ALYSSA MCELWAIN, PhD, is an assistant professor at the Department of Family and Consumer Sciences at University of Wyoming. Her research focuses on adolescent romantic relationships and sexual behavior. She is also interested in both individual and interpersonal predictors of adolescent outcomes and she uses both basic and applied approaches to understanding these critical aspects of adolescence. Email: amcelwai@uwyo.edu 